Afr NEUDQBS

CREATING AND ADAPTING JOBS IN EUROPE IN THE CONTEXT OF A SOCIO-ECOLOGICAL TRANSITION

EXPANSION OF HIGHER EDUCATION AND DeCLININg QUALITY OF DEg REES MirosLaV BebLAVY,

MARIYA TETERYATNIKOVA,

ANNA-ELISABETH THU

NEUjO BS Working PAPER No. 4.4.2 B

3JUNE 2013
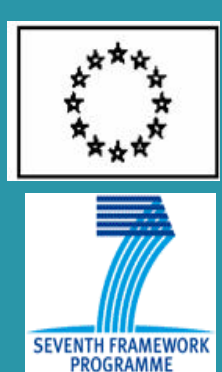

NEUJO BS Working Documents are intended to give an indication of work being conducted within the NEUJOBS research project and to stimulate reactions from other experts in the field. Texts published in this series are ultimately destined for academic publishing. The views expressed in this paper are those of the authors and do not necessarily represent any institution with which they are affiliated. See the back page for more information about the NEUJOBS project.

Available for free downloading from the N EU JOBS website (http://www.neujobs.eu)

@ M iroslav Beblavy, Mariya Teteryatnikova, A nna-Elisabeth Thun, 2013 


\title{
Expansion of higher education and declining quality of degrees
}

\author{
Miroslav Beblavy, Mariya Teteryatnikova, Anna-Elisabeth Thum
}

June 3, 2013

\begin{abstract}
In this paper we study theoretically how the expansion of higher education could be associated with several factors indicating a decline in the quality of degrees. We assume that the expansion of tertiary education happens through three channels and show how they are likely to reduce average study time, average wages and increase grades. Firstly, universities have an incentive through public and private funding schemes to increase their student body beyond a level where they can keep their requirements on a high level. Secondly, due to skill-biased technological change, employers have the incentive to employ mostly labour with a higher education degree. Thirdly, students have the incentive to acquire a college degree due to the employment rules, the university application rules and through the rising social reputation of education. We develop a parsimonious dynamic model in which a student, a college and an employer repeatedly make decisions about requirement levels, performance and wage levels. Our model shows that if (1) universities have the incentive to decrease entry requirements, (2) employers are more likely to employ labour with a higher education degree and (3) all types of students enroll in colleges, the grade will not necessarily act as a mechanism to make weaker students study to catch up with the more able students. In order to reestablish a quality guaranteeing mechanism, entry requirements should be set to a higher level.
\end{abstract}




\section{Introduction ${ }^{1}$}

In this paper we study theoretically how the expansion of higher education could be associated with several factors indicating a decline in the quality of degrees. In particular we are interested in how the expansion of higher education - together with a decrease in university requirements resulting from budgetary considerations - might be associated with a decline in average studying time (student effort), an increase in average grades and a decrease in average wages provided to university graduates. By a declining quality of degrees we therefore refer to a situation in which college requirements and studying time have decreased, grades are inflated and wages awarded to college graduates are declining.

Studying time is an indicator of quality of degrees that has recently gained attention. In the United States a decline in full-time college students' studying time has been observed empirically and has gained in importance as a subject of interest both academically and politically (Arum and Roksa 2011; Babcock and Marks 2010a and Babcock and Marks 2010b; OECD 2012; The Economist 2012; Washington Post 2012; Boston Globe $2012^{2}$ ). In Australia, Hall (2010) and McInnis and Hartley (2002) find that studying time decreases. In Europe, the decrease in studying time has been less in focus of studies than in the US. Most of the academic and public debate on a possible decline in studying time is national and concerns lower studying time in a particular country in comparison to other European countries (Bekhradnia 2012; Sastry and Bekhradnia 2007; Bekhradnia 2012; Eurostudent 2005, 2008, 2012; BBC news 2007; The Irish Times 2012; University Post 2011; The Independent 2013). Bekhradnia (2012:7) finds that in the UK degrees take less time to complete than those of European counterparts and that less studying time per week is spent - a characteristic which seems to apply mainly to post 1992 universities according to Bekhradnia (2012).

Declining studying time has been associated with improved learning technology (Babcock and Marks 2010a,b, Darmody and Smyth 2008, Fischer 2011, Gomis-Porqueras et al 2011). However, Babcock and Marks (2010 a, b) note that this can only be part of the reason. Dolton, Marcenaro and Navarro (2001) confirm this by showing that time spent in formal university study is positively related to student performance. Another identified reason is the growing financial pressure on students as tuition fees increase lead to an increase in working students and therefore possibly also a decrease in hours spent studying (BaffoeBonnie and Golden 2007; Hall 2010; Purcell 2010; Moreau and Leathwood 2006 and McCaig 2011; Manthei and Gilmore 2005). Especially in Europe findings indicate that there was an increase in part-time over full-time students. Hakkinen (2006) finds that in Finland 50 percent of students were working in 2000, which increased the time-to-degree. Working students spend 19 hours per week studying whereas non-working students spend 35 hours per week studying. Moreau and Leathwood (2006) find that students' engagement in paid work has increased in England. Eurostudent (2005) finds that more than 50 percent of students in

\footnotetext{
${ }^{1}$ Corresponding author: Anna-Elisabeth Thum at anna.thum@ceps.eu. We would like to thank Richard Spady, Lucia Kurekova and Marcela Veselkova for interesting comments and insights.

${ }^{2}$ It should be noted that the amount of time US secondary students spend on homework has not changed dramatically over the last 20 years. At high school, students did not study more in the 1940s than they did in the 1960s-1980s (Gill and Schlossmann 2003). However, according to Larson (2001), American children and asolescents spend less time on homework than their Asian or European counterparts and have more discretionary time at their disposal than their counterparts.
} 
Europe are employed. In the Netherlands and Estonia the student employment rate amounts to two thirds. At the same time Eurostudent (2005) provides evidence that students who work for 11 to 15 hours a week spend less time studying. In Germany and Romania the impact is 7 hours less and in Bulgaria, the Czech Republic and Lithuania one hour less. Babcock and Marks (2010 a,b) show that even when controlling for part-time students by studying only full-time students, studying time declines. The increase in part-time students alone therefore does not seem to be a sufficient explanation for the decrease in studying time.

Most of the prominent work in the relevant US literature associates declining studying time with a decrease in college requirements and standards. This decrease arises from a set of reasons related to a more vulnerable position of the faculty staff (Brint 2011; Clotfelter, 2011; Arum and Roksa 2011; Bok 2006; Johnson 20002; Babcock and Marks 20101; Fischer 2011; Clack 2011): the amount of temporary positions as opposed to permanent positions has increased, publication pressure has risen and student evaluations matter more for securing an academic job. Grade inflation has also been documented and associated with decreasing studying time (Johnson 2003; Rojstaczer 2011; Rojstaczer and Healey 2010). Decline in studying time has also been associated with the fact that college enrollment rates increase and less well prepared, less motivated students enter campus (Brint 2011, Bound, Lovenheim and Turner 2009; Clack 2011). The increase in college enrollment rates has been accredited less importance in the debate about quality of degrees, but - taken together with a decrease in college requirements - it may have a considerable impact on the time spent studying (Briggs 2010). Briggs (2010) predicts a decline in the number of average hours spent studying as the fraction of students entering college increases, but has not given a clear theory on how this could actually happen.

The contribution of this paper is to deliver a theoretical reasoning of how the expansion of tertiary education - together with a decrease in college requirements - could decrease average time spent studying, average wages attributed to college graduates and contribute to grade inflation. In our paper we propose a model in which a university, multiple employers and a student play a dynamic game with incomplete information. We focus on the undergraduate tertiary level of education since universities are ranked according to teaching quality, entry and achievement requirements and future employability of students ${ }^{3}$. In our model, expansion of education reduces average studying time because expansion turns out to be a low-ability expansion (the number of low-ability students accepted to university, whose studying time is zero, increases while the number of high ability students stay the same). Machin and McNally (2007:11) already raise this possibility. An expansion towards more low ability students entering college could be taking place because (1) college requirements decrease as a consequence of universities setting requirements so as to maximize the pool of students, (2) all students being better off if they get accepted to a university with a high rank and (3) because employers are more likely to employ highly skilled individuals ${ }^{4}$. Our model shows that under these three conditions, the grade will not necessarily act as a mechanism to make weaker students study to catch up with the more able students. In order to reestablish a quality guaranteeing mechanism, entry requirements should be set to

\footnotetext{
${ }^{3}$ In the way the ranking of universities is modelled we do not address such factors as diversity of faculty research profile, faculty publications and citations, which are relevant determinants for the graduate programs.

${ }^{4}$ By 'highly skilled' individuals we mean those with a university degree.
} 
a higher level. We choose the United Kingdom as an empirical example of our model since students in the United Kingdom seem to be spending little time studying compared to their continental European counterparts (Eurostudent 2011 and Bekhradnia 2012). Furthermore, universities in the United Kingdom might be more strongly affected by the need for a large number of students than continental European universities. The reason for this is that the United Kingdom is among the countries with the largest share of private funding through student fees with 26\% in 2009 (Estermann and Pruvot 2011).

The remainder of the paper is organized as follows: the following section provides empirical evidence of tertiary education expansion and decline in quality of higher education in the United Kingdom. Section 3 delineates the theoretical background for our model. Section 4 presents the theoretical model and its assumptions. Finally, section 5 concludes.

\section{Empirical Evidence}

In this section we provide empirical evidence on expansion of tertiary education in the United Kingdom - compared to other European countries - since 1950, of several indicators of quality of higher education and grade inflation in order to empirically support the key variables in our model. In this section we focus on the United Kingdom since students in the United Kingdom seem to be spending little time studying compared to their continental European counterparts (Eurostudent 2011 and Bekhradnia 2012). Furthermore, universities in the United Kingdom might be more strongly affected by the need for a large number of students than continental European universities. The reason for this is that the United Kingdom is among the countries with the largest share of private funding through student fees with $26 \%$ in 2009 (Estermann and Pruvot 2011).

\subsection{Enrollment in higher education}

Expansion of tertiary education needed to be preceded by universalization of upper secondary education (Beblavy et al 2012:2). The United States were the leading country in the expansion and universalization ${ }^{5}$ of upper secondary education in the 20th century. US enrollment rates in the upper secondary sector rose from 18 percent in1910 to 73 percent in1940 (Goldin 1998:347). Europe followed the US example around 30 years later in form of governments' efforts to make upper secondary education available to the masses (Beblavy 2012:2). As a consequence, tertiary education could equally expand (for an excellent review of this expansion see Trow 2005 or Schofer and Meyer 2005) - a phenomenon which has been observable across Europe in different speeds since the 1970s or 1980s (OECD 2012, Eurostat 2006 and Machin and McNally 2007). The OECD (2012:9) measures that in 2012 over 50\% of university-age young adults are enrolled in higher education in OECD countries. Eurostat (2006) show that between 1998 and 2006, students enrolled in tertiary education have risen from 15 million to 19 million in the EU-27 area. Bratti and de Blasio (2008) provide evidence for Italy. Beblavy et al (2012) provide evidence for increasing enrollment in tertiary

\footnotetext{
${ }^{5}$ Beblavy et al (2012) define an expansion of education that passes the 80 percent threshold as 'universalisation'.
} 
education in Germany, Slovakia, Czech Republic, Spain, the United Kingdom and Sweden ${ }^{6}$ In Figure 1 we show enrollment rates in tertiary education in the United Kingdom. We can see that enrollment in higher education increased only slightly between 1953 and 1989 but then surged very quickly and grew by about 400 percent from 5 to 25 percent. Compared to selected other European countries, expansion in the United Kingdom has happened rather abruptly as well as rather late. As Figures 2 to 5 show, expansion of tertiary education happened at different speeds and dynamics across the various countries. Whereas we can observe a rather steady increase in tertiary enrollment rates in Sweden, the expansion in Spain happened more rapidly and more steeply in Spain.

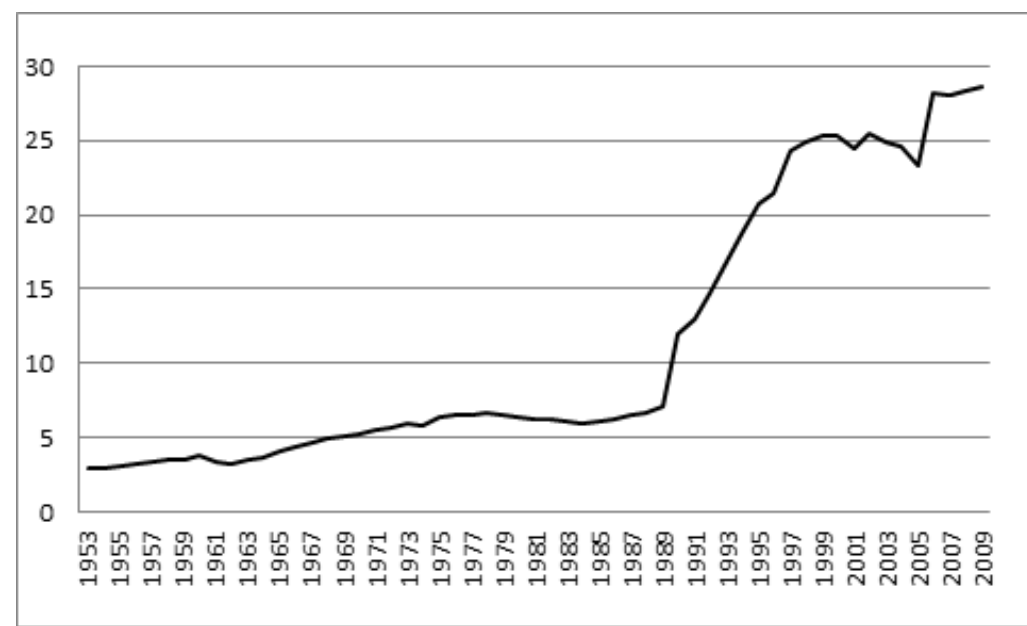

Figure 1: Enrollment rates in tertiary education in the United Kingdom 1953-2009 in percent, Source: Toubeau (2012)

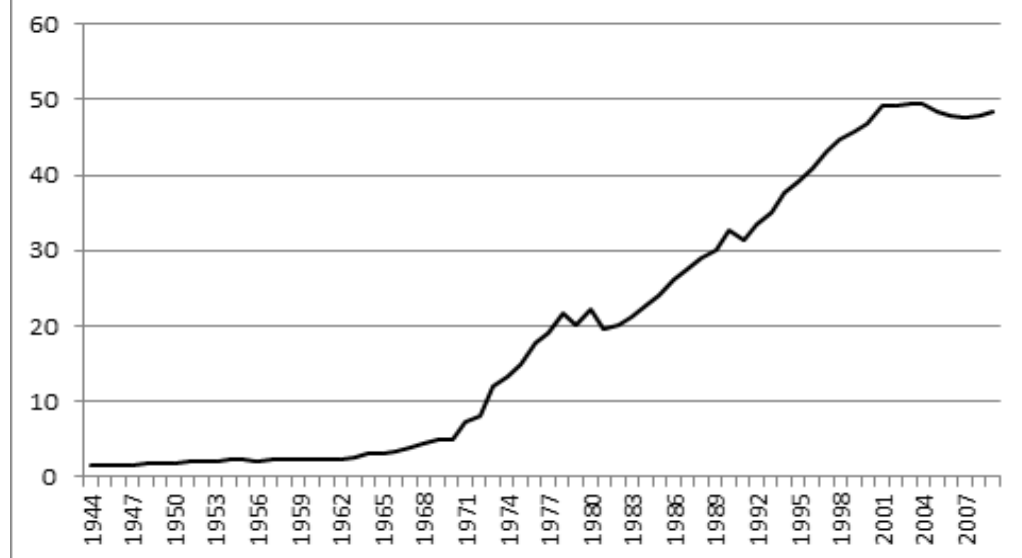

Figure 2: Enrollment rates in tertiary education in Spain 1944-2009 in percent, Source: Pensiero (2012)

\footnotetext{
${ }^{6}$ The graphs show net or gross enrollment rates in tertiary education. Net enrollment rates
} 


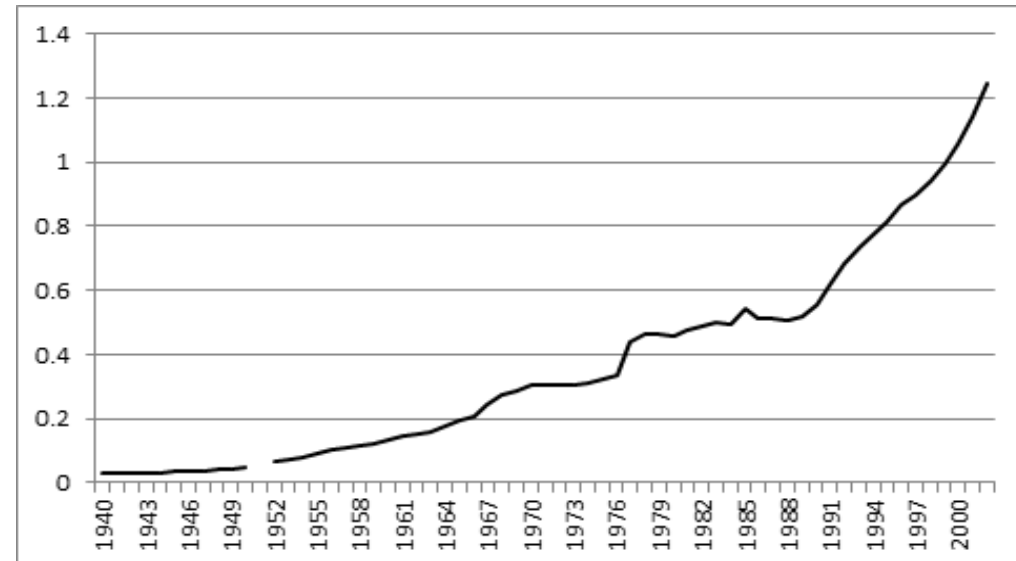

Figure 3: Enrollment rates in tertiary education in Sweden 1940-2002 in percent, Source: Peterson (2012)

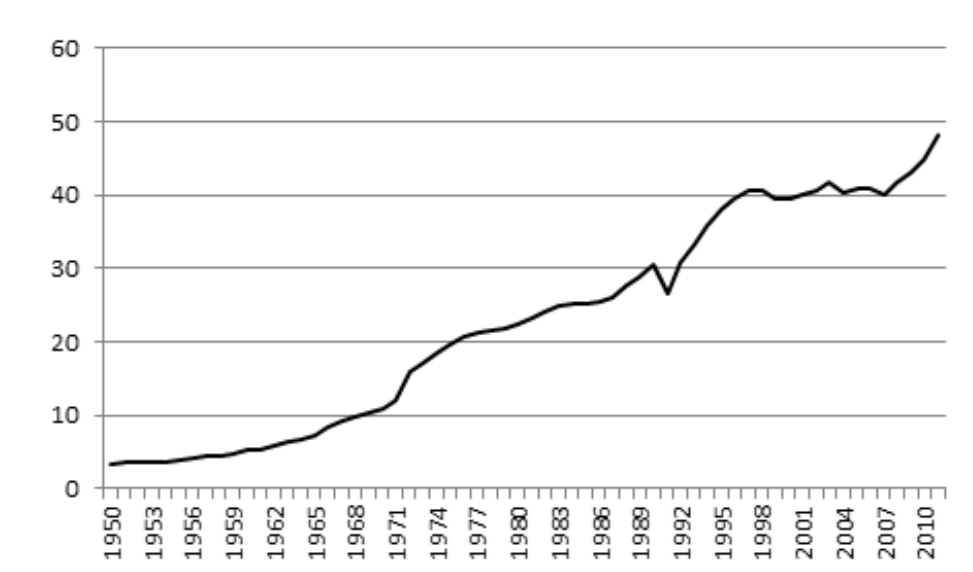

Figure 4: Enrollment rates in tertiary education in Germany 1950-2011 in percent, Source: Thum and Potjagailo (2012)

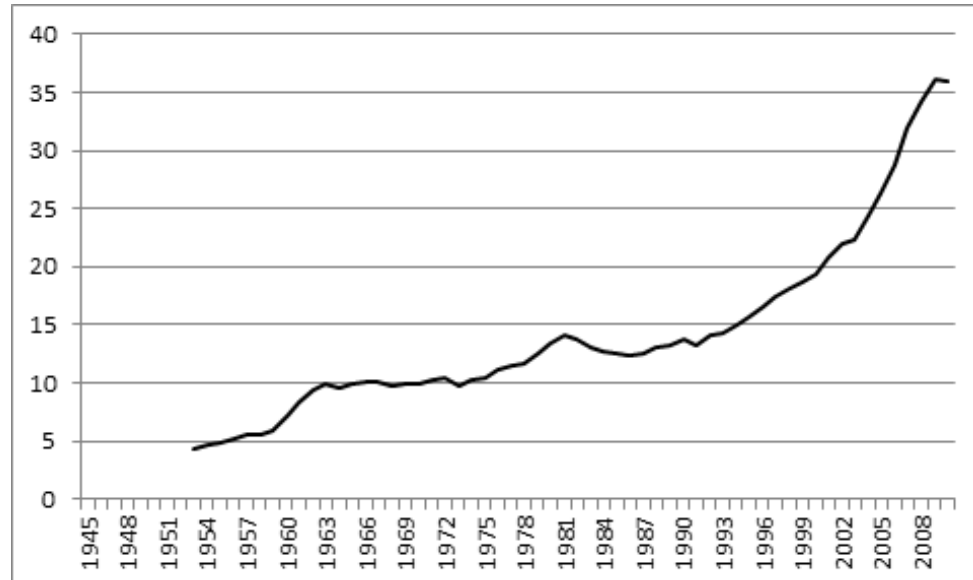

Figure 5: Enrollment rates in tertiary education in Slovakia 1953-2010 in percent, Source: Beblavy et al (2012) 


\subsection{Quality of higher education}

In terms of the quality of higher education, we evaluate studying time and requirements, in which we follow a tradition over the past twenty years (Usher 2009). We add a third element, which is grade inflation as grade setting is a key mechanism in our model. Studying time of full-time students has decreased in the US from 40 hours a week in 1961 to 27 hours a week in 2007 as Babcock and Marks (2010) show. In Europe, there are no such clear-cut numbers. Europe shows a high heterogeneity across countries in the time students spend studying (Eurostudent 2005, 2008, 2011) ${ }^{7}$ : According to the Eurostudent findings, time devoted to studying (classroom time and personal study time) ranges, on the Bachelor level, from 31 hours in France to 38 hours in Italy, and on Master level from 23 hours in Romania to 39 hours in Sweden. Sastry and Bekhradnia (2007) find that university students in the United Kingdom spend 26 hours on teaching and private study in 2006. In Germany however a survey of 1000 students in the state of Hessen state they spend 35 hours for their studies in 2012 (Sparda Bank 2013). These findings are confirmed by Eurostudent (2011). These results have been challenged by Schulmeister and Metzger (2011) who find that students in Hamburg studied only 26 hours in 2009. How these number differ from the past is not clear.

There is national evidence on the fact that standards are declining at universities in the United Kingdom (University World News 2008, The Guardian 2010). Based mainly on qualitative research, House of Commons (2008-2009) finds that stakeholders and actors of higher education institutions in the United Kingdom believe that standards at university have worsened: a university degree is seen as worth less than before from the point of view of employers, students and academics. In the report, employers speak of their observation that students appear to be less motivated and have a less ideal learning approach. Employers are quoted to focus more on previous work experience than on degrees when distinguishing job candidates. Students are quoted in stating that what had been taught at school early was now taught at university (ibid: 112). Academics are quoted, who believe that certain degrees have lost in value compared to five, ten or twenty years ago, essays have declined in quality and students appear to be less well selected (House of Commons 2008-2009: 111). In fact, as shown in Figure 6, requirements to enter college have decreased as acceptance rates have an increasing trend. One reason for higher acceptance rates may be an issue tackled by the House of Commons (2008-2009), which provide evidence of the academic staff's interest to increase the number of admitted students ${ }^{8}$.

\footnotetext{
${ }^{7}$ Heterogeneity can also be measured across subjects as well as across universities (Bekhradnia 2012).

${ }^{8}$ A quote on funding issues by academics is given in House of Commons (2008-2009): "More particularly it relates to a tacit understanding amongst university staff that assessment levels and methods shall be geared mainly, if not exclusively, to the need to retain as many students as possible for the subsequent years and for graduation."
} 


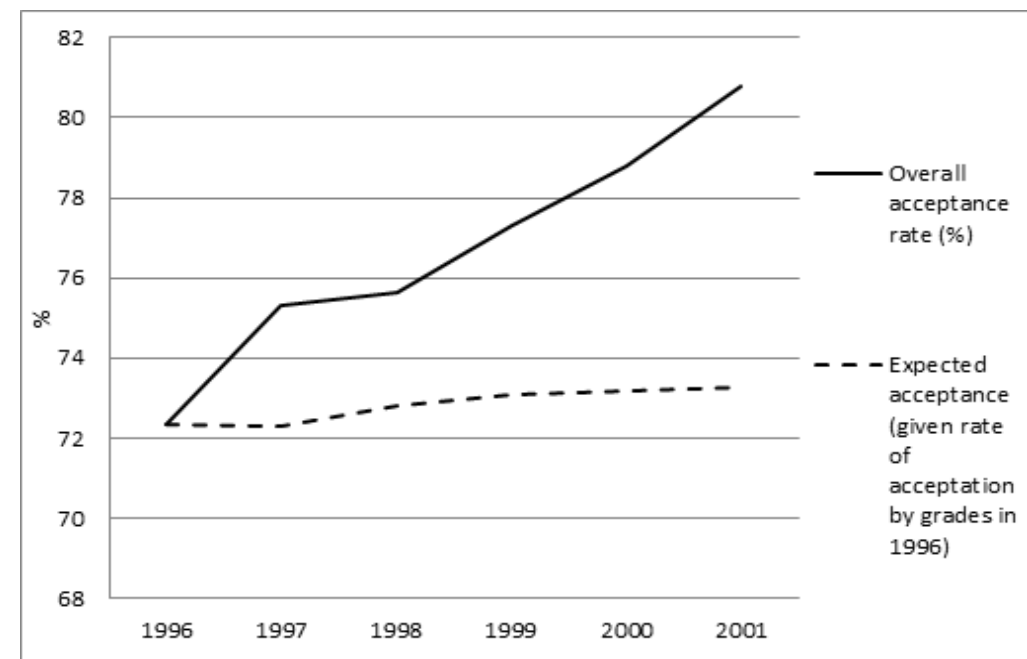

Figure 6: Decreasing enrollment requirement at university in UK for females - males follow a similar pattern (1996-2001), Source: Abbott and Leslie (2004) in Toubeau (2012), database 'Universities and Colleges Admissions Service (UCAS)'

Evidence on grade inflation in the US has been provided by Rojstaczer and Healey (2010) and Rojstaczer (2011), who show that 43 percent of grades at four-year universities are As. This signifies an increase of 28 percentage points since 1960. In the United Kingdom, based on the annually collected Higher Education Statistics Agency (HESA) student record, House of Commons (2008-2009) finds that between 1994 and 2008 the good honours degrees - understood as an upper second or a first class honours degree - awarded has risen. Yorke (2009) finds that between 1994 and 2002 this rise was most concentrated in the elite "Russell Group" universities and between 2002 and 2007 the rise was more evenly spread. Among other reasons Yorke in House of Commons (2008-2009) gives as explanations for an improvements in grades the fact that there might have been changes in the student entry profile of higher education institutions. This has not been empirically proven, however.

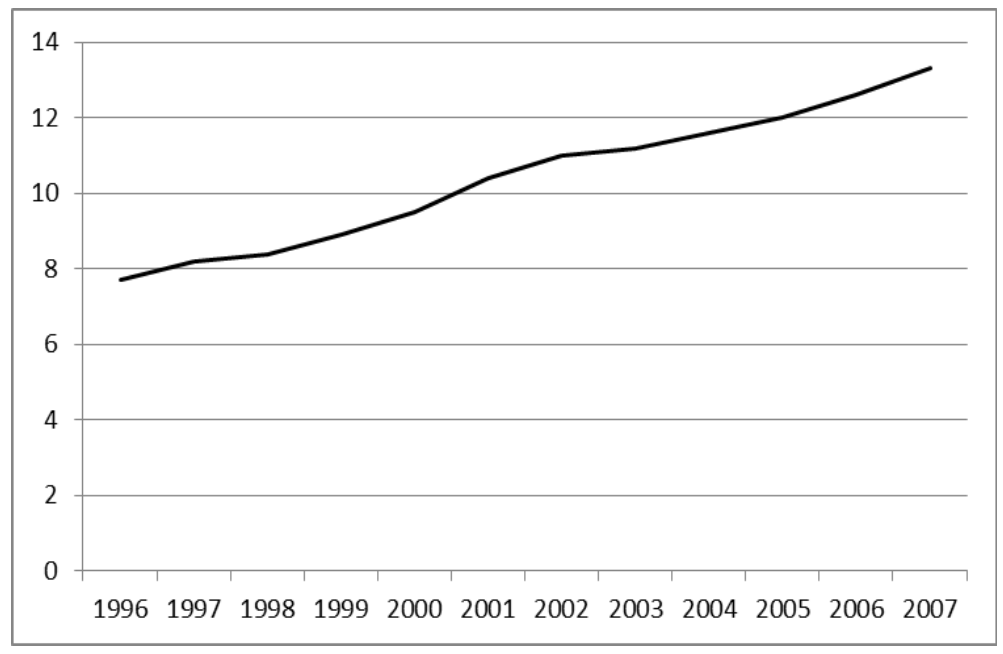

Figure 7: Percentage of upper class first class grades awarded by higher education institutes in the United Kingdom, Source: Higher Education Statistics Agency 


\section{Theoretical Background}

In this section we discuss various economic theories that form the backbone of our model presented in Section 4. Our model is characterized by three distinguishing features that explain the expansion of tertiary education and that we will show how education expansion may lead to a potential decrease in studying effort under certain circumstances:

1. The value of high skills on the labour market: Employers employ only students who went to university - there is a quest for highly skilled individuals. It is important to note here that by "high skilled" individuals we refer to those who went to university. They can be of low or high (innate) ability.

2. The role of universities and the value of expansion: Universities maximize the number of students accepted since funding obtained by university increases with the number of students.

3. The rising importance of university degrees: All potential students are strictly better off if they get accepted to university and the rank of this university is high enough to guarantee them a job.

Below we describe the theoretical basis for each of these features of the model.

\subsection{The value of high skills on the labour market}

The employer employs only students with high skills ${ }^{9}$. He or she is modelled based on a screening model (Stiglitz 1975; Rothschild and Stiglitz 1976; Arrow 1973 and Wiles 1974) an education economic model in which the employer is mainly interested in high educational attainment when making hiring decisions on a potential employee. In a screening model the employer cannot observe the actual ability of potential employees and he or she therefore screens applicants according to their educational attainment to determine an applicant's ability of learning. Hiring applicants with university degrees reduces the employer's risk of hiring someone with a diminished capacity for learning. Implicit characteristics of this model, upon which results are dependent, are: (1) students with higher ability are better in absolute terms; the ranking of abilities is unambiguous (such screening is called hierarchical), (2) labor supply is inelastic, (3) individuals have perfect information on their own abilities, (4) on-the-job screening is not possible, (5) screening is exact, (6) the information acquired is general, in the sense that it is not firm specific (Stiglitz 1975:286). In the screening model as in Stiglitz (1975) there can be a separating equilibrium or a pooling equilibrium ${ }^{10}$ : the latter characterizes a situation in which all workers receive the same average wage whereas the former characterizes a situation in which high ability types receive a high wage and low ability types receive a low wage. In both types of equilibria the existence of the low ability type decreases the net income of the high ability type and the existence of the high ability type will provide the low ability type with at least his or her marginal product (Stiglitz 1975:285). The

\footnotetext{
${ }^{9}$ By high skilled individuals we mean those with a with a university/college degree.

${ }^{10}$ In Rothshild and Stiglitz' (1976) screening model the authors show that only the separating equilibrium exists. Similarly, in our model we show that the pooling equilibrium does not exist.
} 
screening model has several implications: Firstly, social returns differ from private returns and are not necessarily positive in the presence of screening. In fact, screening may tend to lead to higher inequality even if the screening mechanism increases the productivity of firms (Stiglitz 1975:299). There is thus a trade-off between distributive versus productivity concerns. Secondly, there is a tendency of over-investment in education especially in publicly funded schools compared to the case of perfect information: Education serves mainly as a signal and therefore education systems should choose the least costly method in providing this signal. In consequence, the screening model is often used as a theoretical basis to decrease public spending on education (Quiggin 1999). Huang and Capelli (2001), Bedard (2001) and Weiss (1995) offer some empirical evidence of the model and of the importance of higher education for employers.

In our model we add - compared to the Stiglitz and Rothschild (1976) model - a new decision-maker, the university, whose requirements affect the wage contract and the studying time. However, given university requirements, the interaction between the students and the employers in each period $t$ is similar to that in other standard models of screening and there exists a unique symmetric perfect Bayesian equilibrium (SPBE) ${ }^{11}$. We are interested in comparative statics, focusing on the effects of university requirements on students' equilibrium studying time, grades and wages. As a further extension in comparison with Stiglitz (1975), we consider an interaction between the decision makers that is repeated over time, with a new student taking decisions in every period. The equilibrium of this repeated interaction is then defined as a set of players strategies and beliefs that constitute a SPBE in each period.

The fact that university degrees determine employment and the wage contract can be bedded into a wider (sociological) theory for the expansion of higher education. Theoretical reasonings that the expansion of tertiary education is linked to economic development (reflected by the employers' interests described above) are termed as socioeconomic functionalist explanations (Beblavy et al. 2012:3). These theories are based on the fact that national economic development creates demand for skills and supply is given through resources created through economic development (Collins 1971; Goldin 1998). This assumption is in line with recent findings and predictions that high skills matter and will matter most on the labour market (CEDEFOP 2010).

\subsection{The role of universities and the value of expansion}

We consider universities as public institutions providing education and making choices according to public choice theory: In public choice models, it is usually assumed that heads of public institutions aim to maximize their own utility. They will promote benefits of the institutions only in a way that it is beneficial to them personally. Niskanen (1968) argues that heads of institutions will benefit from expansion of their institutions beyond the social optimum. A reason for why managers of educational institutions will benefit from an expansion of their institution stems from not-for-profit (NFP) theory (Holland and Ritvo 2008). NFP theory concerns institutions that do not distribute surplus revenues as dividends or profit - such as universities. Surplus revenues should be kept in the institution to serve its

\footnotetext{
${ }^{11} \mathrm{~A}$ perfect Bayesian equilibrium is an equilibrium in a game with incomplete information. It consists of a strategy set and a belief system of the players. A formal definition is given in section 4.4 below.
} 
goals. Not-for-profit theory states that in absence of the profit motive, NFPs tend to expand since that is the way for managers to increase their prestige and personal perquisites. It is therefore not necessary for the income of universities to expand linearly with number of students - it may if students pay tuition or if state pays per student - but even if there are more complicated funding mechanisms, if they lead to immediate or eventual expansion of university budget following an increase in number of students, our condition is satisfied so that a linear assumption about the correlation of university funds with the number of students is an acceptable approximation.

\subsection{The rising importance of university degrees}

The assumption that all potential students are strictly better off if they get accepted to university is based on the features of the labour market, the fact that universities do have the incentive to take up as many students as the government quota - or university capacity allows and the fact that the social reputation of a university degree has risen with the opening of universities to a larger population. Rubinson and Fuller (1992) show that an educational expansion has also occurred as a result of education having become a status symbol. This theoretical explanation for the expansion of tertiary education can be termed sociological

or conflict, competition and organization (Beblavy et al 2012:3). These theories put less emphasis on market powers as an explanatory factors but rather on social status. Due to competition of different status groups on success in education, the expansion of education rises beyond purely functional requirements (Bourdieu and Passeron 1977; Collins 1971 and 1979). In times of high competition among social status groups as can be the case with a rising population - expansion should be more rapid than in times with less competition (Rubinson and Fuller 1992).

\section{The Model}

In this section we construct a parsimonious model to explore theoretically how the expansion of tertiary education can decrease studying time.

Consider the following dynamic model. There are three essential entities that make decisions: a student with ability $a$ that is distributed according to a probability distribution function (p.d.f.) $f$ with support $[\underline{a}, \bar{a}]$, a university and employers. Implicitly, there is also a fourth party - a government or an education authority - that imposes restrictions on the university by setting (a) the maximal increment in the number of students per period (the quota of students) and (b) a rank condition according to which an expansion of the student pool at the university is only allowed if the rank of the university exceeds a certain threshold. In the model, we take the quota of incoming students and the threshold for the rank as given and fixed over time, so that there is no active role for the government.

Time is discrete, $t \in\{1,2, \ldots\}$, and the three decision makers interact repeatedly over time. Each time period a new cohort of students substitutes the previous, so that a new representative student makes decisions at each time $t$. The timing of events is the following:

1. the university sets the level of requirements, $r_{t}$, that determines the entry conditions and the grades; 
2. $M$ employers simultaneously select a wage contract, given the university requirements and the grades;

3. students with ability high enough to be accepted to the university choose the studying effort.

Below we describe each of these steps and the interaction between the decisions of the university, students and the employers in more detail. First, the university sets the level of requirements, $r_{t}$, that determines the entry conditions and the grades. Only students with ability $a>r_{t}$ pass the entry requirements and get accepted to the university. Upon acceptance they can guarantee themselves a positive level of utility, provided that the rank of the university is higher than a certain threshold (below which the wages are zero). Other potential students, with abilities below $r_{t}$, are not accepted and make no study-related decisions; their utility is set to be zero. Thus, all potential students are strictly better off if they get accepted to the university when the rank of the university is high enough to guarantee them a job, and hence the student pool in this case is represented by all students with abilities in $\left(r_{t}, \bar{a}\right]$. Suppose that at $t=1, \underline{a} \ll r_{1}<\bar{a}$. This initial value of requirements is set arbitrarily within the specified range and determines the initial pool of students, $N_{1}$. To make things interesting though we assume that $r_{1}$ is large enough so that the rank of the university at $t=1$ is above the threshold $R$ set by the authorities; this condition is formally stated and discussed below. ${ }^{12}$ At any $t \geq 2$ the requirements, $r_{t}$, are chosen by the university so as to maximize the pool of students, $N_{t}$, within the quota assigned by the authorities. Implicit in this is the idea that the larger the number of students, the larger the funding that the university obtains, either on a public or on a private basis. For this reason the university has an incentive to reduce its requirements and accept all students within the quota. Yet, it can only do so as long as with the new reduced standards its rank, $R_{t}\left(r_{t}\right)$, is above the threshold $R$ set by the authorities. One can think of this as a situation where the authorities care about prestige of the university and in order to promote high standards, they only allow the university to expand when its rank is higher than a certain level. ${ }^{13}$

When the time $t$ requirements are set, the grade of a student with ability $a$ is determined by

$$
g_{t}=\max \left\{s_{t} a-r_{t}, 0\right\}
$$

where $s_{t}$ is the studying time.

Next, $M$ independent employers simultaneously choose the wage contract. They only employ people who went to the university (students with abilities above $r_{t}$ ), conditional on the fact that the university rank is above the publicly known threshold, that is, $R_{t} \geq R$. If $R_{t}<R$, the employers do not employ anyone. The employers are willing to employ students with abilities above a certain level $A$ at wage $w_{H t}$, and those with abilities below $A$ - at wage $w_{L t}$, where $w_{H t}>w_{L t} .{ }^{14}$ However, the employers do not observe the abilities of students

\footnotetext{
${ }^{12}$ See (1).

${ }^{13}$ Notice that even without the prescription from the authorities, the university can only guarantee itself a positive number of students if its rank is above $R$. For instance, when students are obliged to pay an amount $\varepsilon>0$ for their education, no one would apply to the university if the rank is below $R$. This is clear from the specification of students preferences and wages described below.

${ }^{14}$ We assume the most interesting scenario, when $r_{1}<A<\bar{a}$.
} 
and can only judge them from the grades. They select the wage contracts that may pool or separate high- and low-ability students, depending on the employers' beliefs about which types of students will choose which grade. The wage levels, $w_{H t}$ and $w_{L t}$ are determined via a standard Bertrand competition ${ }^{15}$ between employers. Moreover, only two different wages may exist in equilibrium since as we will show, only two different grades - signals of ability, may be observed.

Finally, given the university requirements and the wage contracts of the employers, a student of any ability $a$ decides how much time to allocate to studying. Studying more improves the grade and this may increase the wage if the wage contracts of the employers are designed to separate high- and low-ability students; if the wage contracts are pooling, studying time does not affect the wage. Also, studying reduces the leisure time. The student's utility is increasing in wage and in leisure; therefore, the choice of the amount of studying time depends crucially on the type of the wage contract - pooling or separating. If the contract is pooling, all students tend to choose the same studying time, minimal that is required to receive the grade that grants the employment. If the contract is separating, then high-ability students study more because for them the returns to studying are higher.

More formally, the dilemmas faced at each time period by the university, employers and students, in their chronological order, are described below.

\subsection{University decision making}

The university's funding is proportional to the number of students. In fact, assuming that the tuition fee per student or a government subsidy per student is fixed at a certain level $p$, the total tuition fee or subsidy that the university obtains at time $t$ is $p \cdot N_{t}$, where $N_{t}$ is the number of students. Therefore, the goal of the university at any period $t$ is to maximize the size of its student pool ${ }^{16}$. However, two restrictions are imposed externally. First, at any requirements level set by the university, its rank, $R_{t}$, should not fall below $R$, the fixed given constant. We will refer to $R_{t} \geq R$ as the rank condition. Secondly, at each time $t$ the student pool cannot be increased by more than $\frac{\Delta}{\bar{a}-a}$, the quota extension for the total number of students. This second restriction can arise as a result of regulation by the government or the education authority or it can simply reflect facility constraints at the university, that is unable to extend its studying facilities (such as computers, libraries, study materials and space) faster than at a certain rate. Naturally, $\frac{\Delta}{\bar{a}-\underline{a}}$ should not exceed $1-N_{1}$.

Thus, the university chooses its requirements $r_{t}$ at time $t$ with the objective to expand its student pool subject to two constraints:

$$
\begin{aligned}
N_{t}\left(r_{t}\right) & \rightarrow \max _{r_{t}} \\
\text { s.t. } N_{t} & \leq N_{t-1}\left(r_{t-1}\right)+\frac{\Delta}{\bar{a}-\underline{a}} \\
R_{t}\left(r_{t}\right) & \geq R
\end{aligned}
$$

\footnotetext{
${ }^{15}$ In a Bertrand competition, sellers set prices simultaneously (in our case the employers set wages). Buyers take these prices as given and set quantities (in our case students set effort).

${ }^{16}$ This assumption is consistent with empirical obseravations delineated in Section 2.
} 
where

$$
N_{t}=\int_{r_{t}}^{\bar{a}} f(a) d a
$$

and

$$
R_{t}\left(r_{t}\right)=\gamma \frac{T}{N_{t}}+\delta r_{t}+\eta A v w_{t}+\xi
$$

The definition of the rank accounts for the teaching quality as captured by $\frac{T}{N_{t}}-$ the ratio of the number of teachers to the number of students $\left(T<1\right.$ and reasonably $T<N_{1}$, the initial number of students), the level of entry and grade requirements, $r_{t}$, the employment prospects of time $t$ student cohort as captured by the average wage, $A v w_{t}$, and other factors - included in constant term $\xi$. The weights $\gamma, \delta$ and $\eta$ are all positive constants and $\gamma+\delta+\eta<1$. The value of $R$ is arbitrary; however, the interesting case is when it is neither too high, nor too low. Namely, assume that $R$ is such that a) initially, at $t=1$ the rank condition is satisfied, that is $R_{1}\left(r_{1}\right)>R$ (in fact, let $R_{1}\left(r_{1}\right) \gg R$ ), and $\mathrm{b}$ ) if requirements decline to the lowest possible level, $r_{t}=\underline{a}$, when all students are accepted to the university, the rank condition does not hold, $R_{t}(\underline{a})<R$. Given the definition of the rank above and using the expression for the average wage that will be derived later, this means that

$\gamma T+\delta \underline{a}+\eta \frac{w_{H t} \bar{a}-w_{L t} \underline{a}-A\left(w_{H t}-w_{L t}\right)}{\bar{a}-\underline{a}}+\xi<R \ll \gamma T \frac{\bar{a}-\underline{a}}{\bar{a}-r_{1}}+\delta r_{1}+\eta \frac{w_{H t} \bar{a}-w_{L t} r_{1}-A\left(w_{H t}-w_{L t}\right)}{\bar{a}-r_{1}}+\xi$

\subsection{Employers' decision making}

There are $M$ independent employers in the market. For simplicity assume that $M=2$; the analysis for $M>2$ can be easily extended. The employers have identical technology that is characterized by the feature that all workers with ability above $A$ (high-ability workers) can perform the work that entitles them to the same wage $w_{H t}$. Also, all workers with ability below $A$ (low-ability workers) can do the work that entitles them to the same wage $w_{L t}$. Assume that $r_{1}<A<\bar{a}$. In equilibrium, each employer seeks to maximize his expected profit, equal to the expected work productivity of the employee net of the wage payment. We assume that the work productivity of a high-ability individual is equal to his ability times constant factor $x_{H}$ and the work productivity of a low-ability individual is equal to his ability times constant factor $x_{L}$. We consider $x_{L} \leq x_{H}$ to make sure that the work productivity (and the equilibrium wage) of a high-ability individual is higher than the work productivity (and the equilibrium wage) of a low-ability individual. The wages $w_{H t}$ and $w_{L t}$ are determined endogenously, via standard Bertrand competition between the employers.

Since the ability is not observable by the employers, they form beliefs about the ability based on the grade that the job applicant receives at the university. That is, having observed the grade $g_{t}$, the employers assign some probability to the fact that the worker is of high-ability type (even for off-the-equilibrium path choices of $g_{t}$ ). Given these beliefs, the employers design the wage contract that either "pools" or "separates" different types of workers, so that wages are allocated to workers consistently with the beliefs.

Consider first the following beliefs of the employers:

- $g_{t} \geq \bar{g}_{t}$ corresponds to $a \geq A$ 
- $g_{t}<\bar{g}_{t}$ corresponds to $a<A$

for some threshold grade $\bar{g}_{t}$. These beliefs lead to a separating contract that offers the high wage $w_{H t}$ to anyone with the grade $g_{t} \geq \bar{g}_{t}$ and the low wage $w_{L t}$ to anyone with the grade $g_{t}<\bar{g}_{t}$. Later, in section 5 , we show that the separating beliefs of the type described above, with a uniquely defined level of $\bar{g}_{t}$, are actually the only equilibrium beliefs of employers.

Moreover, the employment takes place and the wages are paid only if the rank condition is satisfied, $R_{t} \geq R$. If it is not satisfied, the employers are not interested in employing anyone (wages are zero).

\subsection{Student decision making}

Given the wage contract of the employers, a representative student with ability $a>r_{t}$ who is accepted to college at time $t$, chooses the time for study and for leisure with the objective to maximize his or her utility at time $t$. If the wage contract is separating, of the type described above, the optimization problem of a student is

$$
\begin{aligned}
& u\left(l_{t}, w_{t}\right)= l_{t}^{\alpha} w_{t}^{\beta} \rightarrow \max _{l_{t}} \\
& \text { s.t. } l_{t}+ s_{t}=1 \\
& g_{t}= \max \left\{s_{t} a-r_{t}, 0\right\} \\
& w_{t}= \begin{cases}w_{H t} & \text { if } R_{t}\left(r_{t}\right) \geq R \text { and } g_{t} \geq \bar{g}_{t} \\
w_{L t} & \text { if } R_{t}\left(r_{t}\right) \geq R \text { and } g_{t}<\bar{g}_{t} \\
0 & \text { if } R_{t}\left(r_{t}\right)<R\end{cases} \\
& \alpha, \beta>0
\end{aligned}
$$

As it was mentioned earlier, $l_{t}$ and $s_{t}$ denote leisure and studying time, respectively, $g_{t}$ is the grade, and $w_{t}$ is the wage. Given the university requirements, $r_{t}$, a grade $g_{t}$ is obtained if a student with ability $a$ studies for $s_{t}$ units of time. The student is employed only if the rank condition holds and then the wage is either $w_{H t}$ if the student's grade is above the threshold $\bar{g}_{t}$ set by the employer, or $w_{L t}$ if the grade is below this threshold.

\subsection{Equilibrium}

Equilibrium in period $t$ is a standard symmetric perfect Bayesian equilibrium, where all decision makers achieve their objectives subject to the constraints they face and the beliefs of the employers are a) the same, b) "correct" on the equilibrium path, that is, confirmed by the rational choices of high- and low-ability students. Formally, equilibrium is the combination of requirements $r_{t}$ set by the university, the beliefs and the wage contract of the employers and studying times $s_{t}$ chosen by students with all abilities $a \in\left(r_{t}, \bar{a}\right]$ such that:

1. the size of the student pool, $N_{t}$, is maximized subject to $N_{t} \leq N_{t-1}\left(r_{t-1}\right)+\frac{\Delta}{\bar{a}-\underline{a}}$ and $R_{t}\left(r_{t}\right) \geq R$ 
2. the employer's beliefs on the equilibrium path are correct, i.e. consistent with the choices of students. If the corresponding wage contract is separating, workers with ability above $A$ receive the wage $w_{H t}$, workers with ability below $A$ receive the wage $w_{L t}$ and both wages are determined via Bertrand competition between the employers; if the wage contract is pooling, all workers receive the same fixed wage, determined via Bertrand competition;

3. the utility of any student with ability $a \in\left(r_{t}, \bar{a}\right]$ is maximized given the employers' beliefs (on and off the equilibrium path), wage contract, the university requirements and the definition of a grade, $g_{t}=\max \left\{s_{t} a-r_{t}, 0\right\}$;

4. the beliefs of the employers off the equilibrium path are arbitrary.

Below we characterize the equilibrium in any period $t \geq 2 .{ }^{17}$ As we will demonstrate, this equilibrium is unique.The equilibrium of the entire model is then defined as a situation where in each $t \geq 2$ the SPBE of is played.

\section{Results}

In the following assume for the sake of simplicity that abilities of students are distributed uniformly on $[\underline{a}, \bar{a}]$, so that $f$ is the p.d.f. of the uniform distribution, $f(a)=\frac{1}{\bar{a}-a}$ on $[\underline{a}, \bar{a}]$. Then the c.d.f. is $F(a)=\frac{a-a}{\bar{a}-a}$ for $a \in(\underline{a}, \bar{a}]$ (0 below $\underline{a}$ and 1 above $\left.\bar{a}\right)$ and the truncated p.d.f. $\tilde{f}_{t}-$ with the support on the interval $\left(r_{t}, \bar{a}\right]$ for $\underline{a} \leq r_{t}<\bar{a}-$ is defined as

$$
\widetilde{f}_{t}(a)=\frac{f(a)}{F(\bar{a})-F\left(r_{t}\right)}=\frac{1}{\bar{a}-\underline{a}} \cdot 1 /\left(1-\frac{r_{t}-\underline{a}}{\bar{a}-\underline{a}}\right)=\frac{1}{\bar{a}-r_{t}}
$$

Our first proposition states that as soon as the threshold $A$, separating high- and lowability students is high enough, the beliefs of the employers and the corresponding separating wage contract of the type described above are in fact equilibrium beliefs and contracts in any period $t$.

Proposition 1 If the threshold of abilities $A$ is sufficiently high, then the set of strategies and employers' beliefs characterized below constitutes an equilibrium at any $t \geq 2$ :

1. The university requirements are defined recursively by $r_{t}=\max \left\{r_{t-1}-\Delta, r^{*}\right\}$, where $r^{*}$ is the unique solution of $R_{t}\left(r_{t}\right)=R$. Given the initial requirements $r_{1}, r_{t}$ is defined uniquely in every $t \geq 2$ :

$$
\begin{aligned}
& r_{t}=r_{1}-(t-1) \Delta \quad \text { if } r_{1}-(t-1) \Delta>r^{*} \\
& r_{t}=r^{*} \quad \text { otherwise }
\end{aligned}
$$

\footnotetext{
${ }^{17}$ Recall that period 1 requirements are set exogenously and predetermine the initial size of the student pool $N_{1}$.
} 
2. The beliefs of the employers are such that all students with the grade $g_{t} \geq \bar{g}_{t}$ are of high ability (with $a \geq A$ ) and all the other students are of low ability (with $a<A$ ), where the threshold grade, $\bar{g}_{t}$, is equal to

$$
\bar{g}_{t}=A\left(1-\left(\frac{w_{L t}}{w_{H t}}\right)^{\frac{\beta}{\alpha}}\right)-r_{t}
$$

The corresponding separating wage contract offers the high wage $w_{H t}$ to students with $g_{t} \geq \bar{g}_{t}$ and the low wage $w_{L t}$ to students with $g_{t}<\bar{g}_{t}$. The wages, $w_{H t}$ and $w_{L t}$, are equal to

$$
\begin{aligned}
& w_{H t}=\frac{x_{H}}{2}(\bar{a}+A) \\
& w_{L t}=\frac{x_{L}}{2}\left(r_{t}+A\right)
\end{aligned}
$$

3. The studying time of the student of any ability $a<A$ is 0 , while the studying time of the student of any ability $a \geq A$ is

$$
\bar{s}_{t}=\frac{\bar{g}_{t}+r_{t}}{a}=\frac{A\left(1-\left(\frac{w_{L t}}{w_{H t}}\right)^{\frac{\beta}{\alpha}}\right)}{a}
$$

These studying times lead to $g_{t}=0$ and $g_{t}=\bar{g}_{t}$, respectively. Both types of students accept the offered wage contract and earn wages $w_{H t}$ (if of high type) and $w_{L t}$ (if of low type).

The next proposition states the "uniqueness" result. Namely, it claims that the separating equilibrium described in Proposition 3.1 is unique and no pooling equilibrium exists.

Proposition 2 At any $t \geq 2$, there exists no equilibrium in which the wage contract of the employers is pooling.

The proofs of Proposition 3.1 and 3.2 are provided in the Appendix.

Thus, the unique equilibrium outcome at any time $t \geq 2$ is such that (a) the university sets the requirements that are by $\Delta$ lower than the ones in the previous period, as soon as this level does not fall below the lowest acceptable threshold, $r^{*}$; (b) the employers offer the separating wage contract that allocates high wage to students of high ability and low wage to students of low ability, and the wages are determined ’̀ la Bertrand; (c) the students either do not study or study just enough to obtain the threshold grade $\bar{g}_{t}$ and accept the wage contract of the employers.

It is easy to see that the long-run equilibrium value of requirements is $r^{*}$, the value at which the rank condition holds as equality, $R_{t}\left(r^{*}\right)=R$. This induces the long-run value of the threshold grade

$$
\bar{g}^{*}=A\left(1-\left(\frac{w_{L}^{*}}{w_{H}^{*}}\right)^{\frac{\beta}{\alpha}}\right)-r^{*}=A\left(1-\left(\frac{x_{L}}{x_{H}}\right)^{\frac{\beta}{\alpha}}\left(\frac{r^{*}+A}{\bar{a}+A}\right)^{\frac{\beta}{\alpha}}\right)-r^{*}
$$


The long-run studying time of any low-ability student is 0 , while long-run studying time of any high-ability student is

$$
\bar{s}^{*}=\frac{A\left(1-\left(\frac{w_{L}^{*}}{w_{H}^{*}}\right)^{\frac{\beta}{\alpha}}\right)}{a}=\frac{A\left(1-\left(\frac{x_{L}}{x_{H}}\right)^{\frac{\beta}{\alpha}}\left(\frac{r^{*}+A}{\bar{a}+A}\right)^{\frac{\beta}{\alpha}}\right)}{a}
$$

We are interested in the effects that the university requirements have on equilibrium studying time, grades and wages. Notice that the equilibrium wage of high-ability students (with $a \geq A$ ) is constant, unaffected by $r_{t}$, while the wage of low-ability students (with $a<A$ ) is increasing in $r_{t}$, that is, it declines when $r_{t}$ declines. This is so because Bertrand competition between the employers who have separating beliefs induces them to set $w_{H t}$ equal to the expected productivity of the high-type students, $x_{H} E(a \mid a \geq A)$, and $w_{L t}$ equal to the expected productivity of the low-type students, $x_{L} E\left(a \mid r_{t} \leq a<A\right)$. The former conditional expectation is constant since the pool of high-ability graduates, with $a \geq A$, remains the same as requirements decline. On the other hand, the latter conditional expectation moves together with $r_{t}$ : smaller $r_{t}$ leads to a larger pool of low-ability graduates, hence their expected ability and wage become smaller.

The equilibrium grade of low-ability students is constant and equal to 0 , while the equilibrium grade of high-ability students, $\bar{g}_{t}$, increases as requirements become lower.

Finally, the equilibrium studying time of low-ability students remains fixed at 0 , while the equilibrium studying time of high-ability students, $\bar{s}_{t}$, increases as $r_{t}$ declines. The reason why the studying time of high-ability students increases has to do with the fact that as $r_{t}$ declines, declining low-to-high wage ratio, $\frac{w_{L t}}{w_{H t}}$, creates incentives for low-ability students to study and receive high wage, i.e. imitate high-ability students. For this not to happen, the studying time required to earn high wage increases, by just enough to discourage imitation by low types.

These effects of the requirements on equilibrium studying time, grades and on wages induce prediction for the effects on the average/expected equilibrium studying time, $A v s_{t}$, the average/expected equilibrium grade, $A v g_{t}$, and the average/expected equilibrium wage, $A v w_{t}$, of time $t$ cohort of students. Clearly, the average wage declines because the wage and the number of high-ability students are fixed, while the wage of low-ability students decreases and the number of low-ability students becomes larger.

On the other hand, the effects of declining university requirements on the average grade and average studying time are not so straightforward. Comparative statics results (derived in the Appendix) suggest that as the requirements decline, the average grade increases and the average studying time decreases, with the latter being true at least as soon as (i) the ratio of productivity factors, $\frac{x_{L}}{x_{H}}$, is sufficiently low and/or (ii) the ratio of students' preferences for leisure or wages $\frac{\beta}{\alpha}$ is sufficiently small and high types constitute only a relatively small proportion of the total student pool. Intuitively, as requirements become weaker, the average grade increases because the threshold grade, $\bar{g}_{t}$, increases and hence, even though the number of high-ability students remains the same, their grades rise and this turns out to overcompensate an increase in the pool of low-ability students whose grade is zero. Similarly, the decline in average studying time is a result of an increase in the number of low-ability students, whose studying time is zero. This effect turns out to outweigh an increase in the 
studying time of high-ability students, at least as soon as the impact of the declining low-tohigh wage ratio (that increases $\bar{s}_{t}$ ) is muted by low productivity factors ratio, $\frac{x_{L}}{x_{H}}$, and/or if students' preferences allocate sufficiently higher weight to leisure than to wages (so that $\bar{s}_{t}$ of high-ability students does not increase much) and high types constitute only a relatively small proportion of the total student pool. ${ }^{18}$

The proposition below summarizes these conclusions:

Proposition 3 The equilibrium of the model is characterized by the following comparative statics:

1. The equilibrium wage of high-ability students, $w_{H t}$, is constant, independent of $r_{t}$, while the equilibrium wage of low-ability students, $w_{L t}$, decreases when $r_{t}$ declines.

2. The equilibrium studying time of low-ability students is fixed at 0 , while the equilibrium studying time of high-ability students increases when $r_{t}$ declines. As more low-ability students enter university, the increased studying time of the high ability students will not compensate the growing number of low ability students and average studying time will decline.

3. The equilibrium grade of low-ability students is fixed at 0, while the equilibrium grade of high-ability students increases when $r_{t}$ declines.

4. The average equilibrium wage, Avw $w_{t}$, decreases and the average equilibrium grade, Avg, increases when $r_{t}$ declines. The average equilibrium studying time, Avs $s_{t}$, decreases at least as soon as (i) $\frac{x_{L}}{x_{H}}$ is sufficiently small and/or (ii) $\frac{\beta}{\alpha}$ is sufficiently small and $A$ is sufficiently large.

\section{Conclusion}

In this paper we set out to study theoretically how the expansion of higher education could be associated with several factors indicating a decline in the quality of degrees. In particular we are interested in how the expansion of higher education - together with a decrease in university requirements resulting from budgetary considerations - might be associated with a decline in average studying time (student effort), grade inflation and a decrease in average wages provided to university graduates. We constructed a model in which a university, multiple employers and a student play a dynamic game with incomplete information. This model can be interpreted as an extension of the Rothschild and Stiglitz (1976) and Stiglitz (1975) model of screening in which the employer needs to employ a mechanism to sort employees into highly performing on low performing workers. Other previous theoretical models are also forming the basis of our model: universities are modelled as non-for-profit organizations in which managers are interested in expansion of their institution.

\footnotetext{
${ }^{18}$ Notice that the restriction on $A$ to be sufficiently high has been actually imposed already earlier, in order to guarantee the existence of the separating equilibrium in this model.
} 
Empirical evidence for the United Kingdom suggests that indeed there has been an expansion of enrollment in higher education and a decline in the quality of degrees. Expansion of higher education has started in the late 1980s and standards are observed to be declining by low studying time compared to continental European counterparts, grade inflation, increasing acceptance rates as well as lower perceived standards at university.

In our model expansion of education reduces average studying time because expansion is modelled as a low-ability expansion (the number of low-ability students accepted to university, whose studying time is zero, increases while the number of high ability students stay the same). Machin and McNally (2007:11) already raise this possibility. This is the case because (1) college requirements decrease as a consequence of universities setting requirements so as to maximize the pool of students, (2) all students being better off if they get accepted to a university with a high rank and (3) employers give a high wage to those who have a high grade. Our model shows that under these circumstances, the grade will not necessarily act as a mechanism to make weaker students study to catch up with the more able students. In order to reestablish a quality guaranteeing mechanism, entry requirements should be set to a higher level. 


\section{References}

[1] Abbott A and Leslie D (2004): 'Recent Trends in Higher Education Applications and Acceptances', Education Economics, 12, 67-86.

[2] Arrow, K. (1973): 'Higher education as a filter', Journal of Public Economics vol. 2, pp.193-216.

[3] Arum, R. and J. Roksa (2011): Academically Adrift: Limited Learning on College Campuses, Chicago: University of Chicago Press.

[4] BBC News (2007): Students in England 'work less'. Undergraduates in England spend less time studying per week than their European counterparts, a report says, available at http://news.bbc.co.uk/2/hi/uk_news/education/7011121.stm

[5] Babcock, P. and M. Marks (2010a): Leisure, College, USA: The decline in student study time, American Enterprise for Public Policy Research.

[6] Babcock, P. and M. Marks (2010b): The falling time cost of college: evidence form half a century of time use data, The Review of Economics and Statistics, MIT Press, vol. $93(2)$, pages 468-478, May.

[7] Baffoe-Bonnie, J. and L. Golden (2007): Work-Study: Time Use Trade-offs, Student Work Hours and Implications for Youth Employment Policy. SSRN eLibrary. Available at: http://papers.ssrn.com/sol3/papers.cfm?abstract_id=1078688

[8] Bedard, K. (2001): Human Capital versus Signaling Models: University Access and High School Dropouts, Journal of Political Economy 2001, vol. 109, no. 4

[9] Beblavy, M., M. Veselkova, N. Pensiero, E. Peterson, A.-E. Thum and S. Toubeau (2012): Lessons from the expansion of upper secondary education for the expansion of tertiary education, NEUJOBS working paper D4.4.1. available at www.neujobs.eu

[10] Bekhradnia, B. (2012): The Academic Experience of Students in English Universities, HEPI report, avaliable at http://www.hepi.ac.uk/files/AcademicExpereinceStudentsEnglishUnivesitiesReportFullNoEmbargo.p

[11] Bourdieu, P. and J.-C. Passeron (1977): Reproduction of education, society and culture, London: Sage.

[12] Brint, S. (2011): Undergraduate Student Orientations in the United States: Academically Adrift? Forthcoming in Bildung and Erziehung.

[13] Bok, D. (2006): Our under-achieving colleges: a candid look at how much students learn and why they should be learning more, Princeton: Princeton University Press.

[14] Bound, J., M. Lovenheim and S. Turner (2009): Why have college completion rates declined? An analysis of changing student preparation and collegiate resources, NBER working paper No 15556, Cambridge, MA: National Bureau of Economic Research. 
[15] Briggs, W. (2010): Students studying less: shocking report, accessed online from http://wmbriggs.com/blog/?p=2605

[16] CEDEFOP (2010): Skills supply and demand in Europe; Medium-term forecast up to 2020, Luxemburg: Publications Office of the European Union

[17] Clack, J. (2011) : Studying and Grades: When more is less and less is more, Editorial to Bioscene, Journal of College Biology Teaching.

[18] Clotfelter, C. (2011): Big-time sports in American universities, Cambridge: Cambridge University Press.

[19] Collins, R. (1971): Functional and conflict theories of educational stratification, American Sociological Review 36, 1002-1019.

[20] Collins, R. (1979): The credential society: A historical sociology of education and stratification. New York: Academic.

[21] Darmody, M. and E. Smyth (2008): Full-time students? Term-time employment among higher education students in Ireland. Journal of Education and Work 21(4): 349-362.

[22] Dolton, P., O. Marcenaro and L. Navarro (2001): The effective use of student time: a stochastic frontier production function case study, Center for Economics of Education.

[23] Estermann, T. and B. Pruvot (2011): Financially Sustainable Universities II; European universities diversifying income streams, EUA publications, available at http://www.eua.be/Libraries/Publications_homepage_list/Financially_Sustainable_ Universities_II_-_European_universities_diversifying_income_streams.sflb.ashx

[24] Eurostat (2006): Youth in Europe. A statistical portrait, Eurostat Statistical Books, available at http://epp.eurostat.ec.europa.eu/cache/ITY_OFFPUB/KS-78-09920/EN/KS-78-09-920-EN.PDF

[25] Eurostudent (2005): Eurostudent Report 2005; Social and Economic Conditions of Student Life in Europe, available at http://www.eurostudent.eu/results/reports

[26] Eurostudent (2008): Social and Economic Conditions of Student Life in Europe; Synopsis of indicators | Final report | Eurostudent IV 2005-2008; http://www.eurostudent.eu/download_files/documents/EIV_Synopsis_of_Indicators.pdf

[27] Eurostudent (2011): Social and Economic Conditions of Student Life in Europe; Synopsis of indicators | Final report | Eurostudent IV 2008-2011; http://www.eurostudent.eu/download_files/documents/EIV_Synopsis_of_Indicators.pdf

[28] Eurostudent (2012): The European Higher Education Area in 2012: Bologna Process Implementation Report, available at http://eacea.ec.europa.eu/education/eurydice/documents/thematic_reports/138EN.pdf 
[29] Fischer, M. (2010): Eight theories on why college students are studying less, The Atlantic Wire, http://www.theatlanticwire.com/entertainment/2010/07/8-theories-onwhy-college-kids-are-studying-less/23827/

[30] Gill, B. and S. Schlossmann (2003): A nation at rest: the American way of homework, Educational Evaluation and Policy Analysis Fall 2003, Vol. 25, No. 3, pp. 319-337.

[31] Goldin, C. (1988): America's graduation from high school: The evolution and spread of secondary schooling in the twentieth century, The Journal of Economic History 58 (2): 345-374.

[32] Gomis-Porqueras, P., J. Meinecke and J. Rodrigues-Neto (2011): New Technologies in Higher Education: Lower Attendance and Worse Learning Outcomes? Agenda 18(1), pp. 69-83.

[33] Guile, D. and T. Griffiths (2010): Learning through work experience, Journal of Education and Work 14(1): 113-131.

[34] Häkkinen, Iida. 2006. Working while enrolled in a university: does it pay? Labour Economics 13(2): 167-189.

[35] Hall, Ralph. 2010. The work-study relationship: experiences of full-time university students undertaking part-time employment. Journal of Education and Work 23(5): 439-449.

[36] Holland, T. and R. Ritvo (2008): Nonprofit organizations, New York: Columbia University Press.

[37] House of Commons; Innovation, Universities, Science and Skills Committee (2008-2009): Students and universities, available at http://www.publications.parliament.uk/pa/cm200809/cmselect/cmdius/170/170i.pdf

[38] Huang, F. and P. Capelli (2001): Employee screening: Theory and evidence, NBER Working Papers number 12071

[39] Johnson, V. (2002): Teacher course evaluations and student grades: an academic tango, Chance, 15: 9-16.

[40] Johnson, V. (2003): Grade inflation: A crisis in college education, New York: Springer Verlag.

[41] Larson, R. (2001): How U.S. children and adolescents spend time: what does it (and doesn't) tell us about their development? Current Directions in Psychological Science, 10 (5), October 2001, pp. 160-165.

[42] Machin, S. and S. McNally (2007): Tertiary education systems and labour markets, OECD Tertiary Review

[43] Manthei, R. and A. Gilmore (2005): The effect of paid employment on students' lives, Education and Training 47(3), 202-215. 
[44] McCaig, Colin. 2011. Trajectories of higher education system differentiation: structural policy-making and the impact of tuition fees in England and Australia. Journal of Education and Work 24(1-2): 7-25.

[45] McInnis, C. and R. Hartlet (2002): Managing study and work:; The impact of fulltime study and paid work on the undergraduate experience in Australian universities, Department of Education, Science and Training, University of Canberra.

[46] Moreau, Marie-Pierre, and Carole Leathwood. 2006. "Balancing Paid Work and Studies: Working (-Class) Students in Higher Education." Studies in Higher Education 31(1): $23-42$.

[47] Niskanen (1968): 'The peculiar economics of bureaucracy', American Economic Review vol. 58, pp.293-305.

[48] OECD (2012): How marks and education policies shape students' ambitions, OECD, Paris, France.

[49] Purcell, K. (2010): Flexible employment, student labour and the changing structure of the UK labour market in university cities. Centro de Estudos da Metropole Texto para discussao 007.

[50] Quiggin, J. (1999), 'Human capital theory and education policy in Australia', Australian Economic Review 32(2), 130-44.

[51] Rojstaczer, S. (2011): Grade inflation at America Colleges and Universities, accessed online from http//www.gradeinflation.com

[52] Rojstaczer, S. and C. Healey (2010): Grading in American Colleges and Universities, Teachers College Record.

[53] Rothschild, M. and J.E. Stiglitz (1976): Equilibrium in competitive insurance markets: an essay on the economics of imperfect information, Quarterly Journal of Economics, 90, 630-649.

[54] Rubinson, R. and B. Fuller (1992): Specifying the effects of education on national economic growth, pp. 101-115 in The political construction of education, edited by B. Fuller and R. Rubinson, New York: Praeger.

[55] Sastry, T. and Bekhradnia, B. (2007): The Academic Experience of Students in English Universities (2007 report), HEPI report, available at http://www.hepi.ac.uk/4661309/The-Academic-Experience-of-Students-in-English-Universities-\%282007report\%29.html

[56] Schofer, E. and J. Meyer (2005): The Worldwide Expansion of Higher Education in the Twentieth Century, American Sociological Review 2005 70: 898

[57] Schulmeister, R. and C. Metzger (eds): Die Workload im Bachelor: Zeitbudget und Studierverhalten: Eine empirische Studie, Muenster, Germany: Waxmann 2011 
[58] Sparda Bank (2013): Studierende und Geld, Die erste Internet-Generation der „Digital Natives" im Studium, available at https://www.sparda-hessen.de/pdf/spardahessen/SpardaStudie2012-2013.pdf?et_cid=32\&et_lid=107

[59] Stiglitz, J. (1975): The Theory of "Screening," Education, and the Distribution of Income, The American Economic Review, Vol. 65, No. 3 (Jun., 1975), pp. 283-300

[60] The Boston Globe (2012): College students spending less time studying, May 23, 2012, available at http://www.bostonglobe.com/news/nation/2012/05/22/college-studentsspending-less-time-studying/mnU3XDU5TVUs8VFpzXk8TP/story.html

[61] The Economist (2012): Higher education. not what it used to be. American universities represent declining value for money to their students, The Economist, December 1st 2012.

[62] The Guardian (2010): Why university standards have fallen, available at http://www.guardian.co.uk/commentisfree/2010/mar/10/universities-standardsblair-target

[63] The Independent (2013): Lessons at the school of waiting tables: Working while studying, available at http://www.independent.co.uk/incoming/lessons-at-the-schoolof-waiting-tables-working-while-studying-8609766.html

[64] The Irish Times (2012): Irish pupils spend less time on maths, 11.9.2012, available at http://www.irishtimes.com/newspaper/breaking/2012/0911/breaking38.html

[65] The Washington Post (2012): Is college too easy? As study time falls, debate rises, The Washington Post May 22, 2012, available at http://articles.washingtonpost.com/201205-21/local/35456815_1_college-students-study-time-students-report

[66] Trow, M. (2005), Reflections on the Transition from Elite to Mass to Universal Access: Forms and Phases of Higher Education in Modern Societies since WWII, forthcoming in Handbook of Higher Education, available at http://escholarship.org/uc/item/96p3s213

[67] University Post (2011): Danes study less, and spend less time in class, University of Copenhagen 16.6.2011, available at http://universitypost.dk/article/danes-study-lessand-spend-less-time-class

[68] University World News (2008): UK: Standards in decline at many universities, available at http://www.universityworldnews.com/article.php?story $=20080620085336838$

[69] Usher, A. (2009): Ten Years Back and Ten Years Forward: Developments and Trends in Higher Education in Europe Region, in UNESCO Forum on Higher Education in the Europe Region: Access, Values, Quality and Competitiveness, Topical Contributions, UNESCO 2009.

[70] Weiss (1995): Human capital versus signalling explanations of wages, The Journal of Economic Perspectives, 9(4), 133-154. 
[71] Wiles (1974): 'The correlation between education and earnings: the external-test-notcontent hypothesis', Higher Education vol. 3, pp.43-58

[72] Yorke, M. (2009): Trends in honours degree classifications, 1994-95 to 2006-07, for England, Wales and Northern Ireland, The Higher Education Academy, available at: http://www.heacademy.ac.uk/assets/documents/.../Yorke_Trends.doc 


\section{Appendix}

\section{Proofs}

The proofs of both propositions below are analogous to proofs of the existence and uniqueness of the separating equilibrium in Rothschild and Stiglitz (1976).

\section{Proof of Proposition 3.1}

First, suppose that $R_{t} \geq R$ and consider the optimal choice of students with any ability $a \in\left(r_{t}, \bar{a}\right]$, given the employers' beliefs and the offered wage contract. Students with abilities below and above $A$ will select their studying time, $s_{t}$, so that their utility is maximized. First, observe that the minimal studying time needed to obtain the threshold grade $\bar{g}_{t}$ is

$$
\bar{s}_{t}=\frac{\bar{g}_{t}+r_{t}}{a}
$$

Then the student who chooses $s_{t}<\bar{s}_{t}$ will actually set $s_{t}=0$ (and receive $g_{t}=0$ ) because the grade is costly and until it reaches $\bar{s}_{t}$, there are no benefits to increasing $s_{t}$, given the employers' wage contract. Similarly, any student who chooses $s_{t} \geq \bar{s}_{t}$ will in fact set $s_{t}=\bar{s}_{t}$ (and receive $g_{t}=\bar{g}_{t}$ ), since further increases would merely incur costs with no corresponding benefits. Everyone will therefore set either $s_{t}=0$ or $s_{t}=\bar{s}_{t}$.

Given the wage contract and the fact just deduced, if the employers' beliefs are to be consistent, then students with ability $a<A$ must set $s_{t}=0$, while students with ability $a \geq A$ must set $s_{t}=\bar{s}_{t}$. To make sure that this is the case and the threshold grade $\bar{g}_{t}$ does separate $a \geq A$ and $a<A$, it needs to be such that the incentive-compatibility constraints hold for any $a \in\left(r_{t}, \bar{a}\right]$. In other words, the low-ability types should have no incentives to imitate the high-ability types and the other way round. Namely, it must be that

$$
\begin{aligned}
u\left(1-\bar{s}_{t}, w_{H t}\right) & >u\left(1, w_{L t}\right) \text { for any } a \geq A \\
u\left(1, w_{L t}\right) & >u\left(1-\bar{s}_{t}, w_{H t}\right) \text { for any } a<A
\end{aligned}
$$

that is,

$$
\begin{aligned}
\left(1-\frac{\bar{g}_{t}+r_{t}}{a}\right)^{\alpha} w_{H t}^{\beta} & >1 \cdot w_{L t}^{\beta} \text { for any } a \geq A \\
1 \cdot w_{L t}^{\beta} & >\left(1-\frac{\bar{g}_{t}+r_{t}}{a}\right)^{\alpha} w_{H t}^{\beta} \text { for any } a<A
\end{aligned}
$$

Both inequalities are fulfilled if and only if at $a=A$ they hold as equalities: ${ }^{19}$

$$
\left(1-\frac{\bar{g}_{t}+r_{t}}{A}\right)^{\alpha} w_{H t}^{\beta}=1 \cdot w_{L t}^{\beta}
$$

This equality identifies $\bar{g}_{t}$ uniquely for any given $w_{L t}, w_{H t}, A$ and $r_{t}$ :

$$
\bar{g}_{t}=A\left(1-\left(\frac{w_{L t}}{w_{H t}}\right)^{\frac{\beta}{\alpha}}\right)-r_{t}
$$

\footnotetext{
${ }^{19}$ Since with continuously distributed abilities $a=A$ has measure 0 , the fact that for $a=A$ the inequality is not strict "does not matter". This is so in a sense that the probability that a student with ability $A$ prefers to not study and obtain low wage - the behavior associated with $a<A$ - is zero.
} 
Now, the proof of the equilibrium still requires (1) to show that as long as $A$ is sufficiently high, no pooling contract chosen by the competitive employer can break the candidate separating equilibrium, (2) to find the equilibrium wages, (3) to specify the equilibrium strategy of the university. Consider each of these points in turn.

(1) Notice that in equilibrium Bertrand competition over wages results in zero profits for each employer. Consider the deviation by one of the employers to the pooling wage contract that is the best (among all pooling contracts) for the students and allows the employer to make positive profits. This best pooling contract offers the single wage that is equal to the average/expected wage in the whole population of students (minus small $\varepsilon>0$ ), and this wage is paid to a student with any grade $g_{t} \geq 0$. The average wage is equal to

$$
\begin{aligned}
A v w_{t} & =\int_{r_{t}}^{A} w_{L t} \tilde{f}_{t}(a) d a+\int_{A}^{\bar{a}} w_{H t} \widetilde{f}_{t}(a) d a=\frac{w_{L t}\left(A-r_{t}\right)}{\bar{a}-r_{t}}+\frac{w_{H t}(\bar{a}-A)}{\bar{a}-r_{t}}= \\
& =\frac{w_{H t} \bar{a}-w_{L t} r_{t}-A\left(w_{H t}-w_{L t}\right)}{\bar{a}-r_{t}}
\end{aligned}
$$

We show that even this best pooling contract cannot be accepted by both types of students, high- and low-ability, as soon as $A$ is sufficiently high. Indeed, at least some high-ability students will not accept this contract if

$$
u\left(1, A v w_{t}\right)<u\left(1-\bar{s}_{t}, w_{H t}\right) \text { for some } a \geq A
$$

or

$$
\left(\frac{w_{H t} \bar{a}-w_{L t} r_{t}-A\left(w_{H t}-w_{L t}\right)}{\bar{a}-r_{t}}\right)^{\beta}<\left(1-\frac{A\left(1-\left(\frac{w_{L t}}{w_{H t}}\right)^{\frac{\beta}{\alpha}}\right)}{a}\right)^{\alpha} w_{H t}^{\beta} \text { for some } a \geq A
$$

It is easy to see that this condition holds for any $w_{H t}>w_{L t}$ if $A=\bar{a}$ and $a>A$. So, for $A$ large enough, high-ability students do not accept the pooling contract and prefer the separating contract instead. Then the deviation to the pooling wage contract is not profitable, and the candidate separating wage contract is an equilibrium.

(2) With separating wage contract, the expected profit of each employer from employing a high-ability student is equal to

$$
E\left(\pi_{t} \mid a \geq A\right)=x_{H} E(a \mid a \geq A)-w_{H t}
$$

Similarly, the expected profit from employing a low-ability student is equal to

$$
E\left(\pi_{t} \mid r_{t} \leq a<A\right)=x_{L} E\left(a \mid r_{t} \leq a<A\right)-w_{L t}
$$


Both employers have the same technology, hence, the standard Bertrand argument leads to zero profits and

$$
\begin{aligned}
w_{H t} & =x_{H} E(a \mid a \geq A)=x_{H} \int_{A}^{\bar{a}} a \frac{1}{\bar{a}-A} d a=\frac{x_{H}}{2}(\bar{a}+A) \\
w_{L t} & =x_{L} E\left(a \mid r_{t} \leq a<A\right)=x_{L} \int_{r_{t}}^{A} a \frac{1}{A-r_{t}} d a=\frac{x_{L}}{2}\left(r_{t}+A\right)
\end{aligned}
$$

where $\frac{1}{\bar{a}-A}$ and $\frac{1}{A-r_{t}}$ are the truncated probability density functions with the support on $[A, \bar{a}]$ and $\left(r_{t}, A\right)$, respectively.

(3) Finally, consider the optimal choice of requirements by the university at time $t$. Given the objective of the university to increase its funds by maximizing the pool of students, the university reduces the requirements by "as much as possible" since this maximizes $N_{t}=\int_{r_{t}}^{\bar{a}} f(a) d a=\frac{\bar{a}-r_{t}}{\bar{a}-a}$. Therefore, as soon as requirements are above $r^{*}$, the level at which the rank condition just holds, the university cuts them back.

Notice that the level of requirements $r^{*}$ exists and is unique. Indeed, consider that using the expression for the average wage in (2) and the expression for $N_{t}$, the rank of the university at time $t$ can be written as:

$$
\begin{aligned}
R_{t}\left(r_{t}\right) & =\gamma \frac{T}{\frac{\bar{a}-r_{t}}{\bar{a}-\underline{a}}}+\delta r_{t}+\eta \frac{w_{H t} \bar{a}-w_{L t} r_{t}-A\left(w_{H t}-w_{L t}\right)}{\bar{a}-r_{t}}+\xi= \\
& =\gamma \frac{T(\bar{a}-\underline{a})}{\left(\bar{a}-r_{t}\right)}+\delta r_{t}+\eta \frac{w_{H t} \bar{a}-w_{L t} r_{t}-A\left(w_{H t}-w_{L t}\right)}{\bar{a}-r_{t}}+\xi
\end{aligned}
$$

All terms in the sum (apart from $\xi$ ) are increasing in $r_{t}$, that is, the rank of the university moves together with the requirements. Therefore, the lowest level of requirements for which the rank condition holds is such that $R_{t}\left(r_{t}\right)=R$. Due to the fact that $R_{t}\left(r_{t}\right)$ is monotonically increasing in $r_{t}$ and $R$ satisfies (1), there exists a unique solution of $R_{t}\left(r_{t}\right)=R$ in $\left(\underline{a}, r_{1}\right)$, which we denote by $r^{*}$.

So, for any $t \geq 2$ as soon as $r_{t-1}<r^{*}\left(r_{1}<r^{*}\right.$ due to the second inequality in (1)) the optimal strategy of the university is to set

$$
r_{t}=\max \left\{r_{t-1}-\Delta, r^{*}\right\}
$$

$r_{t}=r_{t-1}-\Delta$ guarantees that $N_{t}=N_{t-1}\left(r_{t-1}\right)+\frac{\Delta}{\bar{a}-\underline{a}}$, i.e. the quota of students at time $t$ is used fully and the number of students at $t$ is maximized:

$$
\begin{aligned}
\frac{\bar{a}-r_{t}}{\bar{a}-\underline{a}} & =\frac{\bar{a}-r_{t-1}}{\bar{a}-\underline{a}}+\frac{\Delta}{\bar{a}-\underline{a}} \\
r_{t} & =r_{t-1}-\Delta
\end{aligned}
$$

On the other hand, if $r_{t-1}=r^{*}$, then the requirements are not adjusted anymore. ${ }^{20}$

\footnotetext{
${ }^{20}$ In particular, this means that $r^{*}$ is the long-run value of the university requirements at which the rank condition is just satisfied.
} 


\section{Proof of Proposition 3.2}

Consider the candidate pooling equilibrium. The best (for the students) pooling wage contract offers the wage that is equal to the average/expected wage in the whole population of students (see (2)), paid irrespectively of a student's grade. The profits of both employers are zero.

Below we show that there exists another contract such that the deviation by any of the employers to this contract is profitable. Consider the contract that offers $w_{t}=w_{H t}$ (minus small $\varepsilon>0$ ) if $g_{t} \geq \widehat{g}_{t}$ and $w_{t}=w_{L t}$ if $g_{t}<\widehat{g}_{t}$ for some $\widehat{g}_{t}>0$. We prove that there exists $\widehat{g}_{t}$ such that this contract is accepted by high-ability students but rejected by low-ability students, so that the deviating employer raises positive profits.

The contract is accepted by high-ability students, who choose the studying time $\widehat{s}_{t}=\frac{\widehat{g}_{t}+r_{t}}{a}$ (just enough to receive the grade $\widehat{g}_{t}$ ) as soon as

$$
u\left(1, A v w_{t}\right)<u\left(1-\widehat{s}_{t}, w_{H t}\right) \text { for any } a \geq A
$$

Equivalently,

$$
\left(\frac{w_{H t} \bar{a}-w_{L t} r_{t}-A\left(w_{H t}-w_{L t}\right)}{\bar{a}-r_{t}}\right)^{\beta}<\left(1-\frac{\widehat{g}_{t}+r_{t}}{a}\right)^{\alpha} w_{H t}^{\beta} \text { for any } a \geq A
$$

On the other hand, the contract is rejected by low-ability students, who choose the pooling wage contract with $s_{t}=0$ (and $g_{t}=0$ ), as soon as

$$
u\left(1, A v w_{t}\right)>u\left(1-\widehat{s}_{t}, w_{H t}\right) \text { for any } a<A
$$

Equivalently,

$$
\left(\frac{w_{H t} \bar{a}-w_{L t} r_{t}-A\left(w_{H t}-w_{L t}\right)}{\bar{a}-r_{t}}\right)^{\beta}<\left(1-\frac{\widehat{g}_{t}+r_{t}}{a}\right)^{\alpha} w_{H t}^{\beta} \text { for any } a<A
$$

Both conditions, (4) and (5) are satisfied if and only if they hold as equality at $a=A$. Solving this equality for $\widehat{g}_{t}$ produces

$$
\widehat{g}_{t}=A\left(1-\left(\frac{w_{H t} \bar{a}-w_{L t} r_{t}-A\left(w_{H t}-w_{L t}\right)}{\left(\bar{a}-r_{t}\right) w_{H t}}\right)^{\frac{\beta}{\alpha}}\right)-r_{t}
$$

Hence, the deviating contract breaks the candidate pooling equilibrium.

\section{Proof of Proposition 3.3}

We only need to prove part 4 of the proposition. Namely, we need to study the effect of $r_{t}$ on $A v g_{t}$ and $A v s_{t}$. First, notice that

$$
\begin{aligned}
A v g_{t} & =\int_{A}^{\bar{a}} \bar{g}_{t} \widetilde{f}_{t}(a) d a=\bar{g}_{t} \int_{A}^{\bar{a}} \frac{1}{\bar{a}-r_{t}} d a=\bar{g}_{t} \frac{\bar{a}-A}{\bar{a}-r_{t}}=\left[A\left(1-\left(\frac{x_{L}}{x_{H}}\right)^{\frac{\beta}{\alpha}}\left(\frac{r_{t}+A}{\bar{a}+A}\right)^{\frac{\beta}{\alpha}}\right)-r_{t}\right] \bar{a}-A \\
A v s_{t} & =\int_{A}^{\bar{a}-r_{t}} \bar{s}_{t} \widetilde{f}_{t}(a) d a=\int_{A}^{\bar{a}} \frac{\bar{g}_{t}+r_{t}}{a} \frac{1}{\bar{a}-r_{t}} d a=\int_{A}^{\bar{a}} \frac{A\left(1-\left(\frac{w_{L t}}{w_{H t}}\right)^{\frac{\beta}{\alpha}}\right)}{a} \frac{1}{\bar{a}-r_{t}} d a= \\
& =\frac{A\left(1-\left(\frac{w_{L t}}{w_{H t}}\right)^{\frac{\beta}{\alpha}}\right)}{\bar{a}-r_{t}}(\ln \bar{a}-\ln A)=\frac{A\left(1-\left(\frac{x_{L}}{x_{H}}\right)^{\frac{\beta}{\alpha}}\left(\frac{r_{t}+A}{\bar{a}+A}\right)^{\frac{\beta}{\alpha}}\right)}{\bar{a}-r_{t}}(\ln \bar{a}-\ln A)
\end{aligned}
$$


Consider the partial derivatives of $A v g_{t}$ and $A v s_{t}$ with respect to $r_{t}$ and evaluate their sign.

Simple algebra leads to

$$
\begin{aligned}
\frac{\partial A v g_{t}}{\partial r_{t}} & =\frac{\bar{a}-A}{\left(\bar{a}-r_{t}\right)^{2}}\left[A\left(\frac{x_{L}}{x_{H}}\right)^{\frac{\beta}{\alpha}}\left(\frac{r_{t}+A}{\bar{a}+A}\right)^{\frac{\beta-\alpha}{\alpha}}\left(-\left(\frac{r_{t}+A}{\bar{a}+A}\right)-\frac{\beta}{\alpha} \frac{\bar{a}-r_{t}}{\bar{a}+A}\right)+A-\bar{a}\right]<0 \\
\frac{\partial A v s_{t}}{\partial r_{t}} & =\frac{\left(r_{t}+A\right)^{\frac{\beta-\alpha}{\alpha}}}{\left(\bar{a}-r_{t}\right)^{2}} \frac{A(\ln \bar{a}-\ln A)}{(\bar{a}+A)^{\frac{\beta}{\alpha}}}\left[\left(\frac{\bar{a}+A}{r_{t}+A}\right)^{\frac{\beta}{\alpha}}\left(r_{t}+A\right)-\left(\frac{x_{L}}{x_{H}}\right)^{\frac{\beta}{\alpha}}\left(r_{t}+A\right)-\frac{\beta}{\alpha}\left(\frac{x_{L}}{x_{H}}\right)^{\frac{\beta}{\alpha}}\left(\bar{a}-r_{t}\right)\right]
\end{aligned}
$$

The sign of $\frac{\partial A v s_{t}}{\partial r_{t}}$ is positive, at least as soon as (i) $\frac{x_{L}}{x_{H}}$ is sufficiently small and/or (ii) $\frac{\beta}{\alpha}$ is sufficiently small and $A$ is sufficiently large.

Hence, lower $r_{t}$ results in higher $A v g_{t}$ and lower $A v s_{t}$. 


\title{
AвоUT NEUJOBS
}

\author{
“Creating and adapting jobs in Europe in the context of a socio-ecological \\ transition"
}

NEUJOBS is a research project financed by the European Commission under the 7th Framework Programme. Its objective is to analyse likely future developments in the European labour market(s), in view of four major transitions that will impact employment - particularly certain sectors of the labour force and the economy - and European societies in general. What are these transitions? The first is the socioecological transition: a comprehensive change in the patterns of social organisation and culture, production and consumption that will drive humanity beyond the current industrial model towards a more sustainable future. The second is the societal transition, produced by a combination of population ageing, low fertility rates, changing family structures, urbanisation and growing female employment. The third transition concerns new territorial dynamics and the balance between agglomeration and dispersion forces. The fourth is a skills (upgrading) transition and and its likely consequences for employment and (in)equality.

Research Areas

NEUJOBS consists of 23 work packages organised in six groups:

- Group 1 provides a conceptualisation of the socio-ecological transition that constitutes the basis for the other work-packages.

- Group 2 considers in detail the main drivers for change and the resulting relevant policies. Regarding the drivers we analyse the discourse on job quality, educational needs, changes in the organisation of production and in the employment structure. Regarding relevant policies, research in this group assesses the impact of changes in family composition, the effect of labour relations and the issue of financing transition in an era of budget constraints. The regional dimension is taken into account, also in relation to migration flows.

- Group 3 models economic and employment development on the basis of the inputs provided in the previous work packages.

- G roup 4 examines possible employment trends in key sectors of the economy in the light of the transition processes: energy, health care and goods/ services for the ageing population, care services, housing and transport.

- G roup 5 focuses on impact groups, namely those vital for employment growth in the EU: women, the elderly, immigrants and Roma.

- Group 6 is composed of transversal work packages: implications NEUJOBS findings for EU policy-making, dissemination, management and coordination.

For more information, visit: www.neujobs.eu

Project coordinator: Miroslav Beblavý (Miroslav.Beblavy@ext.ceps.eu) 